\title{
C-peptide -A Promising Biomarker Beneath the Radar of Diabetes Therapeutics
} Khushdeep Bandesh ${ }^{1}$ and Avijit Podder ${ }^{2 *}$

${ }^{1}$ Genomics and Molecular Medicine Unit, CSIR-Institute of Genomics and Integrative Biology, Delhi, India ${ }^{2}$ Bioinformatics Infrastructure Facility, Sri Venkateswara College, University of Delhi, Delhi, India

\begin{abstract}
C-peptide is a product of insulin biosynthesis and its independent functional role has been largely overlooked. Administration of C-peptide along with regular insulin therapy tends to comfort or delay late stage diabetic complications. The article collates mechanistic role of C-peptide in diabetes, its clinical measurement and prospective therapeutic potential.
\end{abstract}

\section{Introduction}

In humans, insulin is originally secreted as a 110 amino-acids molecule called pre-proinsulin [1] that undergoes proteolytic cleavage to yield mature insulin and a 31 amino-acid peptide - C-peptide [2]. Both the mature insulin and the C-peptide remain stored in secretory vesicles in pancreatic $\beta$-cells and are released extracellularly in response to increased blood glucose levels [2]. Since its discovery in year 1967, C-peptide was considered a biologically inert molecule that simply enables correct folding and stabilizes $\alpha$ - and $\beta$ - chains of insulin molecule. However, it was in early 1990s that a series of studies established that C-peptide in physiological concentrations significantly improves several diabetes-induced abnormalities and the possibility of C-peptide being a functional molecule was re-evaluated. Alike a 'Swiss army knife', C-peptide has now been known to have multiple functions independent of T2D biology that has reintroduced scientific interest in understanding C-peptide biology. This commentary highlights the importance of monitoring C-peptide levels in diabetes and its crucial role in preventing and comforting late stage complications that otherwise cease to restore by insulin administration alone.

\section{C-peptide as Precise Measure for Endogenous Insulin}

C-peptide is released into bloodstream at an equimolar concentration with that of insulin and is cleared at a constant rate however, the insulin gets cleared variably. C-peptide encounters negligible first-pass metabolism by liver and thus enjoys a much longer plasma half-life (30 mins) than a mere half-life of 5 mins for insulin [3]. Hence, the direct measurement of insulin is inaccurate assessment of its physiological secretion. Also, C-peptide measurement avoids the pitfall of cross-detection of exogenous and endogenous insulin to understand residual function of pancreatic $\beta$ cells in diabetic patients administering insulin. This marks C-peptide as a valuable and precise indicator of insulin release, a critical parameter for clinical management of patients with diabetes. Normal circulating levels of C-peptide depend upon the type of diabetes (Type 1 or Type 2) (i.e. residual $\beta$-cell function) and its duration (i.e. onset of late-stage microvascular complications neuropathy, nephropathy or retinopathy and eventually macrovascular complications- hypertension, cardiovascular diseases, coronary artery disease, etc.).

\section{Mechanistic Role of C-peptide in Diabetes Etiology}

It is well-established that C-peptide serves an important role in insulin synthesis. Remarkably there is a steady increase in number of reports stating new aspects of C-peptide physiology. C-peptide is known to bind in a stereospecific fashion to several human celltypes - endothelial, renal tubular and skin fibroblasts [4]. The binding occurs at specific G protein coupled receptors, probably GPR146 [5]. Upon binding to the cell membrane, C-peptide has been observed to get internalized in mouse fibroblasts Swiss 373 and human embryonic kidney 293 cells [6]. Endosomes are key sorting stations for internalized peptides. Internalized C-peptide has been shown to localize initially to early endosomes before lysosomal degradation in human aortic endothelial cells and umbilical artery smooth muscle cells [7]. Besides, internalized C-peptide has been seen to localize to nucleoli where it binds to histone $\mathrm{H} 4$ and promotes acetylation at lysine residue 16 (H4K16Ac) of promoters of ribosomal RNA genes, thereby enhancing gene transcription [8]. C-peptide has been documented to act via diverse intracellular mechanisms. C-peptide at physiological concentrations in endothelial cells causes influx of $\mathrm{Ca}^{2+}$ increasing intracellular concentrations [9]. Increased $\mathrm{Ca}^{2+}$ levels activate endothelial nitric oxide synthase (eNOS) to boost nitric oxide (NO) synthesis and release which in turn relaxes vascular smooth muscles. This results in an increased blood flow that enhances insulin absorption and consequently glucose utilization. A reduced eNOS activity and a subsequent alteration in micro-circulation is a major pathological factor for development of microvascular complications in diabetes. At physiological concentrations, C-peptide stimulates $\mathrm{Na}+\mathrm{K}+$ ATPase activity primarily via phosphorylation of phospholipase C (PLC), several protein kinase $\mathrm{C}$ (PKC) isoforms, and phosphatidylinositol 3-kinase; and activation of mitogen activated protein kinase (MAPK) system [10]. C-peptide also activates transcription factor zinc E-box binding protein (ZEB) to augment expression of $\mathrm{Na}+\mathrm{K}+\mathrm{ATPase}$ [10]. Besides ZEB, C-peptide stimulates a number of transcription factors essential for cell growth, migration, inflammatory responses, and apoptosis - CREB, ATF, Bcl2, PPAR $\gamma$, SREBF1 and NF-kB [11]. Subsequently eNOS synthesis is upregulated. Inflammation induced vascular damage is a key pathological condition in diabetes. C-peptide has been reported to exhibit anti-inflammatory effects by antagonizing inflammatory cytokine secretion, adhesion molecule expression and reactive oxygen species (ROS) formation in endothelial cells and leukocytes [12,13].

*Corresponding author: Avijit Podder, Bioinformatics Infrastructure, Shri Venketeswara College, University of Delhi, India, E-mail: avijitpodder.83@gmail.com

Received October 03, 2018; Accepted October 22, 2018; Published October 30, 2018

Citation: Bandesh K, Podder A (2018) C-peptide - A Promising Biomarker Beneath the Radar of Diabetes Therapeutics. J Biomol Res Ther 7: 167. doi:10.4172/21677956.1000167

Copyright: (c) 2018 Bandesh K, et al. This is an open-access article distributed under the terms of the Creative Commons Attribution License, which permits unrestricted use, distribution, and reproduction in any medium, provided the original author and source are credited. 
Further, it has been noted that C-peptide may interact synergistically with insulin signaling pathway. C-peptide activates tyrosine kinase to phosphorylate insulin receptor substrate 1 (IRS1), thus mimicking insulin [14]. Unlike insulin, C-peptide inhibits ROS production [15] and hence antagonizes downstream insulin signaling. Also, C-peptide has been demonstrated to regulate the availability of monomeric insulin for activating IR by binding to $\mathrm{Zn}^{2+}$ ions and therefore alter the equilibrium between oligomeric and monomeric insulin [16].

\section{Clinical Measurement of C-peptide}

C-peptide can be estimated by various immunoassays that have been developed to detect its blood and urine levels in an outpatient clinical setting. The physiological levels can be measured in random, fasting and stimulated states [17]. The plasma concentration of C-peptide in an overnight fasted state generally varies between 0.3-0.6 $\mathrm{nM}$ in healthy subjects and postprandial levels may range between 1-3 nM [18]. Its concentration is generally 10-20 times higher in urine than plasma [19]. At room temperature, C-peptide in whole blood is stable for up to 24 hours in EDTA vacutainers however urinary C-peptide for up to 3 days when collected in boric acid container $[20,21]$. The currently available assays to detect C-peptide provide high specificity offering a nearly null crossreactivity to detect C-peptide levels as low as $0.003 \mathrm{nmol} / \mathrm{L}$. In people with normal glucose tolerance, urinary C-peptide to creatinine ratio substantially mirrors 24 hours urinary C-peptide levels and is also a reliable and convenient method of estimation [20]. C-peptide is largely removed from the body by the kidneys. Majority of which gets degraded via peritubular uptake and only $5-10 \%$ of the total C-peptide is excreted unaltered in the urine $[17,20]$. Therefore, during a renal impairment, concentration of C-peptide in blood may be falsely elevated and hence unreliable for correct estimation.

\section{Therapeutic Potential of C-peptide Administration}

So, as described above diabetic complications occur due to secondary systemic damage caused by chronic hyperglycemia and largely contribute to diabetes-related morbidity and mortality. C-peptide deficiency is a characteristic property of Type 1 Diabetes and the late stages of Type 2 Diabetes. C-peptide biosynthesis continues to persist for decades after diabetes onset and remains functionally responsive [22]. Over the past decades, certain rigorous research efforts have highlighted that $\mathrm{C}$-peptide administration alone or in combination with the ongoing insulin therapy is beneficial in protecting organ-specific vascular outcomes in diabetes [22,23]. The findings indicate that patients with advanced stage of diabetes, whose $\beta$-cell function was presumed to have long ceased, will certainly benefit from interventions that preserve $\beta$-cell function or prevent complications. Studies have shown that diabetic patients undergoing C-peptide administration feature marked improvement in vascular blood flow (due to eNOS mediated NO formation and erythrocyte $\mathrm{Na}+/ \mathrm{K}+$-ATPase activation) and capillary diffusion rate leading to an increased capacity of oxygen and glucose uptake $[2,17,19,24,25]$. Apart from this, C-peptide restores left ventricular ejection fraction and stroke volume in diabetic patients like those in healthy controls [26]. At physiological levels, C-peptide exhibits anti-inflammatory effects [2] and stimulates angiogenesis [27]. Therefore, it is beneficial for impaired wound healing, a common ailment observed in advanced diabetics. Diminished glomerular filtration is a key feature of renal failure in diabetes. C-peptide replacement therapy has been observed to reduce hyperpermeability of glomeruli and improve kidney function by restricting excess protein leakage [28-30]. Likewise, a 3- to 6- month administration of insulin accompanied by C-peptide has shown to reinstate nerve dysfunction by reestablishing sensory nerve conduction velocity to $80 \%$ in Type 1 Diabetics presenting early signs of neuropathy [31,32]. Retinopathy is a major diabetic complications and leading cause of blindness. C-peptide acts retino-protective by impeding ROS generation and preventing VEGF induced microvascular leakage across retina in a diabetic eye $[33,34]$.

\section{Conclusion and Future Perspective}

Blood insulin levels are predominantly used to assess a person's response to glycemic conditions which do not reflect the correct endogenous insulin production. Despite several reports that establish a critical and independent role of C-peptide in diabetes etiology, its levels are rarely measured to assess actual endogenous insulin secretion and residual $\beta$ cell function. Diabetes is today an epidemic affecting all world populations regardless of their socioeconomic status, genetic diversity and environment. Decades of intense research efforts globally to understand diabetes physiology have not fully succeeded in providing an appropriate therapeutic intervention for the disease. Considering a large body of documented functions, C-peptide administration along with the regular insulin therapy is beneficial to not only control glucose utilization but also restore normal physiological functioning of various organs in advanced diabetes scenario which may not be achieved otherwise. This combinatorial replacement therapy shall be looked upon for testing in clinical settings to reach an effective diabetes treatment.

\section{References}

1. Stoy J, Edghill EL, Flanagan SE, Ye H, Paz VP, et al. (2007) Insulin gene mutations as a cause of permanent neonatal diabetes. PNAS 104: 15040-15044.

2. Sima Anders AF (2012) Diabetes \& C-peptide- Scientific and Clinical Aspects Springer New York Dordrecht Heidelberg London.

3. Leighton E, Sainsbury CAR, Jones GC (2017) A Practical Review of C-Peptide Testing in Diabetes. Diabetes Ther 8: 475-487.

4. Rigler R, Pramanik A, Jonasson P, Kratz G, Jansson OT, et al. (1999) Specific binding of proinsulin $\mathrm{C}$-peptide to human cell membranes. Proceedings of the National Academy of Sciences 96: 13318-13323.

5. Yosten GL, Kolar GR, Redlinger LJ, Samson WK (2013) Evidence for an interaction between proinsulin C-peptide and GPR146. J Endocrin 218: B1-B8.

6. Lindahl E, Nyman U, Melles E, Sigmundsson K, Ståhlberg M, et al. (2007) Cellular internalization of proinsulin C-peptide. Cell and Mol Lif Sci 64: 479- 486.

7. Luppi P, Geng X, Cifarelli V, Drain P, Trucco M, et al. (2009) C-peptide is internalised in human endothelial and vascular smooth muscle cells via early endosomes. Diabetologia 52: 2218-2228.

8. Lindahl E, Nyman U, Zaman F, Palmberg C, Cascante A, et al. (2010) Proinsulin Cpeptide regulates ribosomal RNA expression. J Bio Chem 285: 3462-3469.

9. Wallerath T, Kunt T, Forst T, Closs El, Lehmann R, et al. (2003) Stimulation of endothelial nitric oxide synthase by proinsulin C-peptide. Nitric Oxide 9: 95-102.

10. Galuska D, Pirkmajer S, Barrès R, Ekberg K, Wahren J, et al. (2011) C-peptide increases $\mathrm{Na}$, K-ATPase expression via PKC- and MAP kinase dependent activation of transcription factor ZEB in human renal tubular cells. PLOS ONE 6: e28294.

11. Hills CE, Brunskill NJ (2009) Cellular and physiological effects of C-peptide. Clin Sci (Lond) 116: 565-574

12. Luppi P, Cifarelli V, Tse H, Piganelli J, Trucco M, et al. (2008) Human C-peptide antagonizes high glucose-induced endothelial dysfunction through the nuclear factor-kappaB pathway. Diabetologia 51: 1534-1543

13. Haidet J, Cifarelli V, Trucco M, Luppi P (2012) C-peptide reduces proinflammatory cytokine secretion in LPS-stimulated U937 monocytes in condition of hyperglycemia. Inflammation Research 61: 27-35. 
Citation: Bandesh K, Podder A (2018) C-peptide - A Promising Biomarker Beneath the Radar of Diabetes Therapeutics. J Biomol Res Ther 7: 167. doi:10.4172/2167-7956.1000167

Page 3 of 3

14. Grunberger G, Qiang X, Li Z, Mathews ST, Sbrissa D, et al. (2001) Molecular basis for the insulinomimetic effects of C-peptide. Diabetologia 44: 1247-1257.

15. Cifarelli V, Geng X, Styche A, Lakomy R, Trucco M, et al. (2011) C-peptide reduces high-glucose-induced apoptosis of endothelial cells and decreases $\mathrm{NAD}(\mathrm{P})$ Hoxidase reactive oxygen species generation in human aortic endothelial cells. Diabetologia 54: 2702-2712.

16. Jörnvall H, Lindahl E, Astorga-Wells J, Lind J, Holmlund A, et al. (2010) Oligomerization and insulin interactions of proinsulin C-peptide: threefold relationships to properties of insulin. Biochemical and Biophysical Research Communications 391: 1561-1566.

17. Jones AG, Hattersley AT (2013) The clinical utility of C-peptide measurement in the care of patients with diabetes. Diabet Med 30: 803-817.

18. Yosten GL, Maric-Bilkan C, Luppi P, Wahren J (2014) Physiological effects and therapeutic potential of proinsulin C-peptide. American Journal of Physiology Endocrinology and Metabolism 307: E955-E968.

19. Horwitz DL, Rubenstein AH, Katz Al (1977) Quantitation of human pancreatic beta-cell function by immunoassay of C-peptide in urine. Diabetes 26: 30-35

20. McDonald TJ, Knight BA, Shields BM, Bowman P, Salzmann MB, et al. (2009) Stability and reproducibility of a single-sample urinary C-peptide/creatinine ratio and its correlation with 24-h urinary C-peptide. Clin Chem 55: 2035-2039.

21. McDonald TJ, Perry MH, Peake RW, Pullan NJ, O'Connor J, et al. (2012) EDTA improves stability of whole blood C-Peptide and insulin to over 24 hours at room temperature. PLoS One 7: e42084.

22. Wahren J, Kallas Å, Sima Anders AF (2012) The Clinical Potential of C-Peptide Replacement in Type 1 Diabetes. Diabetes 61: 761-772.

23. Shpakov AO (2017) Mechanisms of action and therapeutic potential of proinsulin C-peptide. J Evol Biochem Phys 53: 180-190.

24. Forst T, Kunt T, Wilhelm B, Weber MM, Pfützner A, et al. (2008) Role of C-Peptide in the Regulation of Microvascular Blood Flow. Exp Diabetes Res 2008: 176245.
25. Wilhelm B, Kann P, Pfützner A (2008) Influence of C-Peptide on Glucose Utilisation. Exp Diab Res 2008: 769483.

26. Johansson BL, Sundell J, Ekberg K, Jonsson C, Seppänen M, et al. (2004) C-peptide improves adenosine-induced myocardial vasodilation in type 1 diabetes patients. Am J Physiol Endocrinol Metab 286: E14-19.

27. Lim YC, Bhatt MP, Kwon MH, Park D, Na SH, et al. (2015) Proinsulin C-Peptide Prevents Impaired Wound Healing by Activating Angiogenesis in Diabetes. $J$ Invest Derma 135: 269-278.

28. Shaw J, Shetty P, Burns K, Knoll G. (2014) The therapeutic potential of C-peptide in kidney disease: a protocol for a systematic review and metaanalysis. Systematic Reviews 3: 43.

29. Nordquist L, Brown R, Fasching A, Persson P, Palm F, et al. (2009) Proinsulin C-peptide reduces diabetes-induced glomerular hyperfiltration via efferent arteriole dilation and inhibition of tubular sodium reabsorption. Am J Physiol Renal Physiol 297: F1265-F1272.

30. Hills CE, Al-Rasheed N, Al-Rasheed N, Willars GB, Brunskill NJ, et al. (2009) C-peptide reverses TGF-beta1-induced changes in renal proximal tubular cells: implications for treatment of diabetic nephropathy. Am J Physiol Renal Physiol 296: F614-F621.

31. Sima AA, Zhang W, Li ZG, Murakawa Y, Pierson CR, et al. (2004) Molecular alterations underlie nodal and paranodal degeneration in type 1 diabetic neuropathy and are prevented by C-peptide. Diabetes 53: 1556-1563.

32. Ekberg K, Brismar T, Johansson BL, Jonsson B, Lindström $P$, et al. (2003) Amelioration of sensory nerve dysfunction by C-peptide in patients with type 1 diabetes. Diabetes 52: 536-541.

33. Bhatt MP, Lim YC, Ha KS (2014) C-peptide replacement therapy as an emerging strategy for preventing diabetic vasculopathy. Cardiovascular Res 104: 234-244.

34. Lim YC, Bhatt MP, Kwon MH, Park D, Lee S, et al. (2014). Prevention of VEGFmediated microvascular permeability by $\mathrm{C}$-peptide in diabetic mice. Cardiovasc Res 101: 155-164. 